\title{
Grocery Experience Survey: A Canadian Perspective on Service, Product and Management Specifies
}

\author{
Sylvain Charlebois ${ }^{1} \&$ Janet Music $^{1}$ \\ ${ }^{1}$ Faculty of Management/Factulté De Management, Kenneth C. Rowe Management Building, Room 3059, 6100 \\ University Avenue, PO Box 15000, Halifax NS, B3H 4R2, Canada \\ Correspondence: Sylvain Charlebois, Faculty of Management/Factulté De Management, Kenneth C. Rowe \\ Management Building, Room 3059, 6100 University Avenue, PO Box 15000, Halifax NS, B3H 4R2, Canada. \\ Tel: 902-222-4142. E-mail: sylvain.charlebois@dal.ca
}

Received: December 2, $2018 \quad$ Accepted: December 18, $2018 \quad$ Online Published: January 28, 2019

doi:10.5539/jfr.v8n2p15

URL: https://doi.org/10.5539/jfr.v8n2p15

\begin{abstract}
The socio-economic significance of independent grocers has been, for the most part, underappreciated and overlooked for several decades in the Western world. Few studies have been looked at the field in recent years and even less so in Canada. Retail studies have highlighted the sector's evolution, particularly the emergence of multiple channel designs. The primary focus of previous studies has been on food retailing, but not ownership and localized market adaptation. This study intended to identify the limitations of our knowledge related to independent grocers in Canada. By using our study's outcome and identifying key drivers for market adaptation, this study aspires to highlight their somewhat subordinate relationship to government and the difficulties of modernising their business methods. Results show that Canadians regularly visit 2.3 grocery stores on average, 1.29 times a moth for an average duration of 32 minutes. Results also show that service specificity, and to a certain extent, product specificity can provide independent grocers with an advantage. While most consumers value receiving assistance when needed, younger consumers appreciate knowing who works at the grocery store they visit. Trust on ownership is also key in management specificity. This study provides a platform for future research on independently own grocers.
\end{abstract}

Keywords: independent grocers, service quality, product quality, management model

\section{Introduction}

Grocery shopping has changed dramatically in recent years for several reasons. First, corporate and social responsibilities are often undermined by centralized models in food distribution which does not always adapt well to subtle, cultural differences between regions (French, 2008; Bean, 2017). It also has been recognized that major food distributors have failed to effectively serve an increasingly diverse marketplace (Skinner, Pratley and Burnett, 2016). On the other hand, food demand has also changed. Given the change in the role of women in our economy, for example, men grocery shop more often which warrants a different approach (Mortimer and Clarke, 2011). Also, ethnic groups and aboriginal communities have reportedly felt disenfranchised over the years as food selection has not always reflected their communities' diversity (Charlebois and Camp II, 2007; Charlebois, McCormick and Juhasz, 2016; Howard, 2017). Furthermore, it is known that residents of rural areas may have limited access to healthy foods, which leads to higher incidence of diet related health issues, and that smaller grocers in rural areas experience challenges in maintaining fresh produce and other healthy foods available for customers (Le Vallée and Charlebois, 2015; Bardenhagen et al., 2017).

The socio-economic significance of independent grocers has been, for the most part, underappreciated and overlooked for several decades. Few studies have been looked at the field in recent years and even less so in Canada. Studies of retailing have highlighted the sector's long-run evolution, particularly the emergence of multiple channel designs. The focus has been on food retailing and not ownership and localized market adaptation. Countless studies have looked at market trends, logistics, e-commerce and other aspects of distribution which are most often centrally coordinated by major grocers (Cochoy, 2018). What is suspected to be different with independent food retailers is that they respond through collective action designed to justify their commercial and social functions (Charlebois and Summan, 2014; Charlebois, Hansen Sterne and Buhr, 2015). They also counteract the competitive threats as a collective. Recent studies have emphasised the significance of 
trade associations and collective action in grocery wholesaling around the world, but not necessarily on how management can differentiate and strategize differently. Surprisingly, no studies from Canada specifically are found on this subject matter. This study intends to identify limitations of our knowledge related to independent grocers in Canada. By using our study's outcome and identifying key drivers for market adaptation, this study also aspires to highlight their somewhat subordinate relationship to government and the difficulties of modernising their business methods. Of greater significance, this study will show how gradual adjustments to service provided to consumers from diverse cultures by local grocery stores can be achieved (Balazic, Wilcock, Hill and Charlebois, 2013).

\section{Theoretical Framework and Methods}

Inspired by the principle applicant's recent theoretical work on food consumption habits (Charlebois, McCormick and Juhasz, 2016; Charlebois et al., 2017), we probed respondents on determinants consistent with a proposed conceptual model (Figure 1). Three layers of food retailing specificity are explored. First, the present study recognizes that the design of local food systems cannot depend on abstract, formalized models due to the specificity of each experiences (Ballantyne-Brodie and Telalbasic, 2017). Service specificity includes store design, customer service, use of in-store technology and meal kits. Second, related to management-specificity, the study examines how grocers may succeed in turbulent times by trying to overcome the weaknesses of the two dominant paradigms in food retailing (corporate and specialty-regionalized) through business model innovation (Nasser et al., 2011; Massa and Testa, 2011). As such, for this study, features suggested by Morris et al. (2005) are adopted. The aspects include trust, community engagement, transparency of ownership and family values embedded into the operations. Finally, consumers and regulators increasingly demand product-specific characteristics beyond price, including nutrient content, food safety practices, and indicators of impacts on the environment (Gómez et al, 2011). For product-specificity, this study will be using food value chain attributes, which originated from the French filière approach (Raikes, Jensen and Ponte, 2000; Charlebois and Haratifar, 2015).

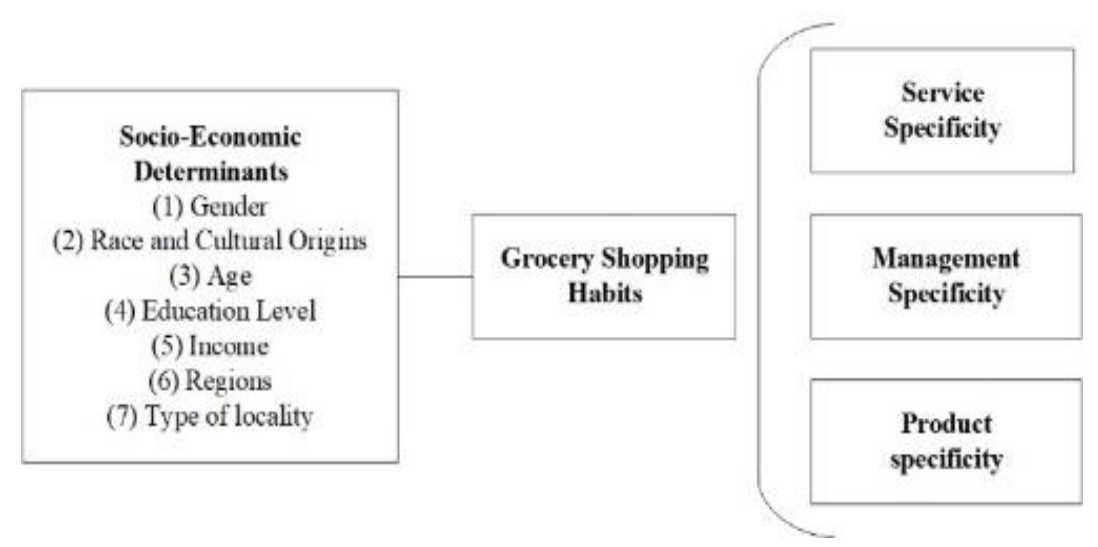

Figure 1. Determinants, Grocery Shopping Habits and Preferences

This category includes several decision factors related to products such as health benefits, local foods, environmental friendliness, freshness, quality food safety and price.

\section{Methodology}

The exploratory study was a consumer-focused quantitative survey. The instrument did not suggest or explain what independent grocers are. The instrument design captured respondents' understanding of grocery shopping in general. Understanding what findings mean to independent grocers was the ultimate exercise in the end. Demographic-based information was collected. This exploratory study was derived from a quantitative analysis of primary data that was obtained from an online survey of adults, aged 18 and over, living in Canada for at least twelve months.

The survey instrument was first designed and pre-tested before its release. To identify technical difficulties and ensure that the questions were clear, an online pilot survey was conducted among Canadian residents in Fall 2018. The final online survey was administered over two days. Using an approach consistent with similar studies on food consumption and trends (Beardsworth \& Bryman, 2004; Redmond \& Griffith, 2004), the survey was widely distributed (in French and English) across the country using Qualtrics, an online data collection and analysis tool, targeting several different regions and socio-economic groups. The sample was randomized but 
controlled in order to get an accurate representation of the Canadian population, based on regions, gender and age. Data was collected from over 1000 respondents, who were asked $(n=1053)$, on a 5-point scale, a variety of questions. Data was collected during the month of October 2018. The first section was about their grocery shopping habits. We measured frequency of visits, types of stores visiting, and distances travelled to shop. The second part was about culinary habits, traditions and dietary restrictions. The third and last part was related to shopping preferences for management, products and service specificities. The sample was indiscriminate, using regional and demographic benchmarks to obtain an accurate representation of the Canadian population. The average completion time for the survey was 6.5 minutes, and the completion rate was $96 \%$. All regions were represented, including the Atlantic region, Quebec, Ontario, the Prairies, the North and British Columbia.

\section{Results}

The first series of questions looked at grocery shopping habits. Overall, $42.3 \%$ of Canadians regularly visit two stores to purchase food. The average Canadian visits 2.3 stores regularly. Regionally, some differences were depicted. More than $20 \%$ of Quebecers only visit one grocery store, while almost $25 \%$ of Atlantic Region respondents visit more than three stores regularly. On frequency, $76 \%$ visit a grocery store at least once a week. The average Canadian will visit a grocery store 5.43 times a month (1.29 times a week). Generations do differ in terms of frequency. Younger respondents tend to visit grocery stores less frequently. This may be due to different lifestyles and family responsibilities. Interestingly, $24 \%$ of respondents from British Columbia visit a store every other day, more so than any other region. When asked about the amount of time spent in a store, the majority of Canadians spend more than 20 minutes per visit. The average Canadian spends roughly 32 minutes per visit. British Columbians appear to spend less time per visit but go more often, while respondents in the Prairies spend more time on a single visit (see Figure 2). Age and gender also appear to generate different results. Almost $60 \%$ of respondents born before 1946 spend between 20 to 30 minutes per visit. As for women, they tend to spend more time per visit.

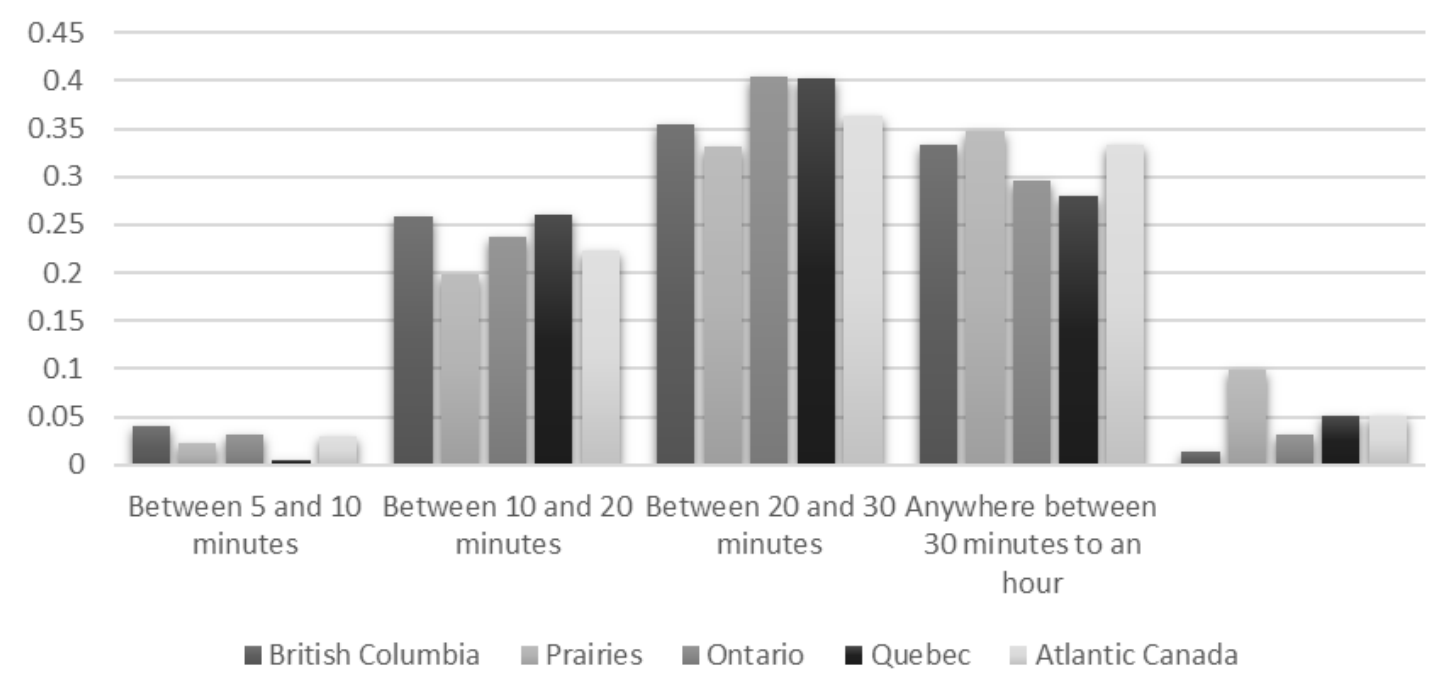

Figure 2. On average, how much time do you spend in a store every visit? (By Region)

Given that online purchasing is fairly new in Canada the survey also covered this area. According to the results, almost half of Canadians don't intend to purchase food online. However, more than $20 \%$ of respondents with a university degree have purchased food online (see Figure 3). The "Click and Collect" service is seen as a gateway strategy for grocers who want to gain some online presence and appears to be more popular with respondents. In fact, more respondents are not planning to use a "Click and Collect" service than online purchasing. 


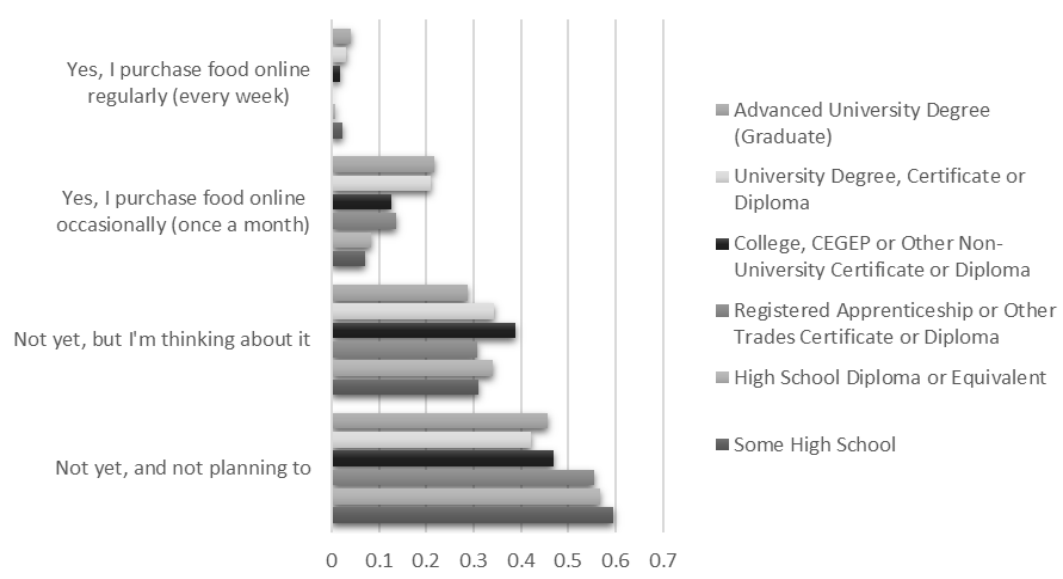

Figure 3. Have you purchased groceries online? (By Education)

Some questions were also asked about transportation and how respondents get to the grocery store. Driving is by far the most popular mode of transportation in Canada. However, 17\% of respondents in Quebec walk while 85\% of respondents in Prairies drive. In addition, technology and the use of self-checkouts was assessed during the survey. $66 \%$ of respondents acknowledged to have used self-checkouts. More than $40 \%$ of respondents who are divorced or separated have never used self-checkouts, while respondents from Quebec appear to be using self-checkouts less frequently or do not have access to them.

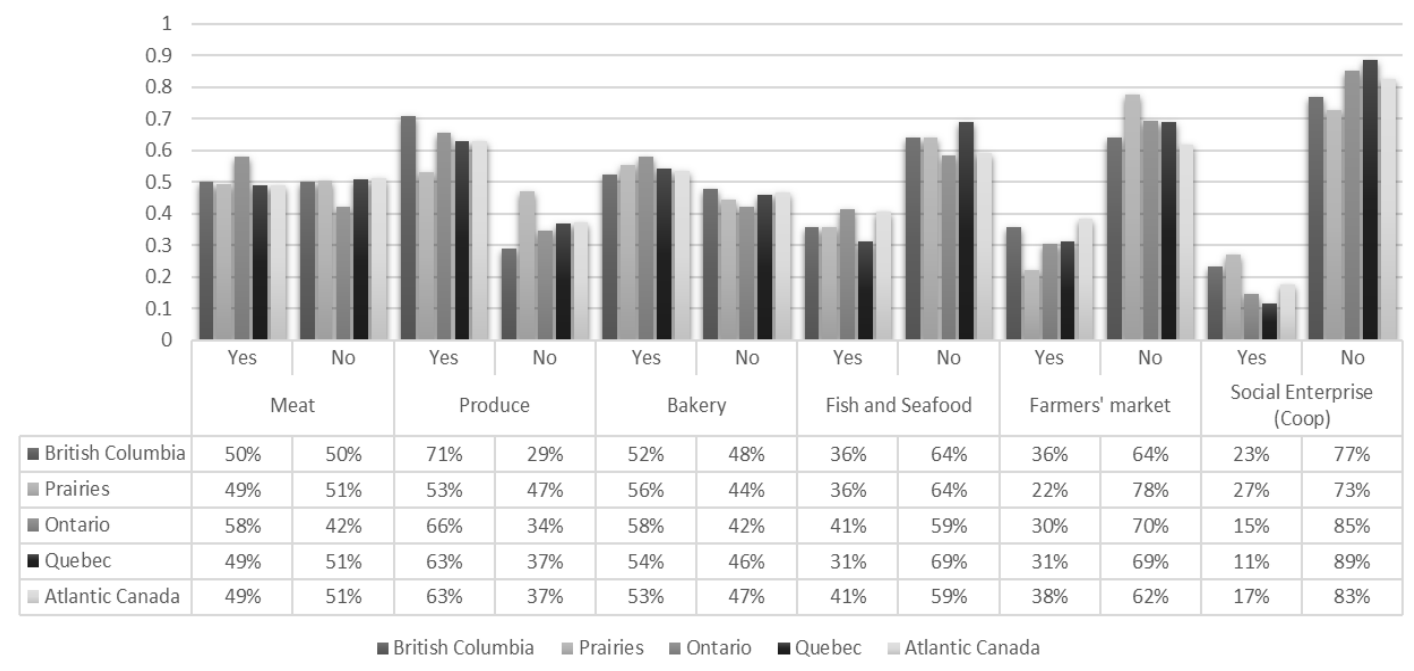

Figure 4. Specialty Stores (By Region)

The next section looked at rotating shopping habits for different food categories. Food stores which solely sell produce seem to be more popular than fish and seafood stores. Regional differences produced interesting results. British Columbians enjoy visiting produce stores, while Ontarians seem to enjoy meat shops more so than other respondents (see Figure 4). Respondents were asked if they often purchased a food product without really known what it is. Respondents in Quebec appear to be more curious than respondents in other regions. It is the only region where the majority of respondents would buy a food product out of curiosity.

Management and ownership specificity were also assessed and results indicated a wide variety of preferences from different demographic groups. The appreciation of where the store was located was measured. A total of $80.6 \%$ of respondents believe location to be critical. Higher income earners appear to prioritize location more so than lower income earners. A total of $83.1 \%$ of respondents enjoy going to a food store where they can buy all of their needs. At the same time, men appear to feel more strongly about shopping in one place than women. Respondents with no children are less likely to enjoy large food stores. Small stores appear to be less appreciated by respondents, but there was slightly more interest in stores where everything can be seen quickly in both 
Ontario and Quebec. Also, knowing who works at a store produced some noteworthy results. There was a strong correlation between age group and knowing people who work in the food store (see Figure 5).

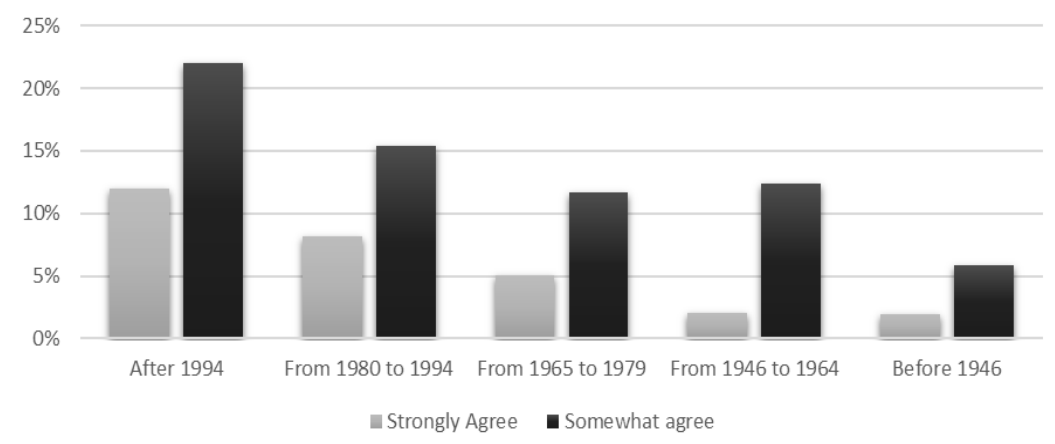

Figure 5. I will pick a food store because I know many people who work there (By Age Group)

Also, the middle class is also different when knowing people. Respondents earning $\$ 75 \mathrm{k}$ to $\$ 99,999$ are more likely to appreciate knowing the manager, not just someone who works there. Furthermore, the middle class, or mid-income earners, appear to see it as important to visit a store owned by a family. We also noticed that respondents from Urban Cores appear to want to know who owns the food store, which may appear counterintuitive. On community engagement, respondents from British Columbia appear to value community engagement slightly more than other respondents. Further, men appear to value trust in ownership more so than women.

On product specificity, certain factors were considered. Overall, quality, price and freshness are the most important factors for respondents (see Figure 6). Respondents in the Atlantic Region appear to value price and quality, while Quebec respondents' value environmental friendliness, much more so than any other regions. In relation to meat products, respondents in Atlantic Region appear to value price and quality, while Quebec respondents' value environmental friendliness. With produce, $36.3 \%$ of respondents believe freshness is the most important factor. As for fish and seafood, freshness is the most important factor, followed by quality and food safety. Fish and seafood are the only category where price is not in the top 3 of decision factors. For all categories, freshness and quality were the top choices for respondents.

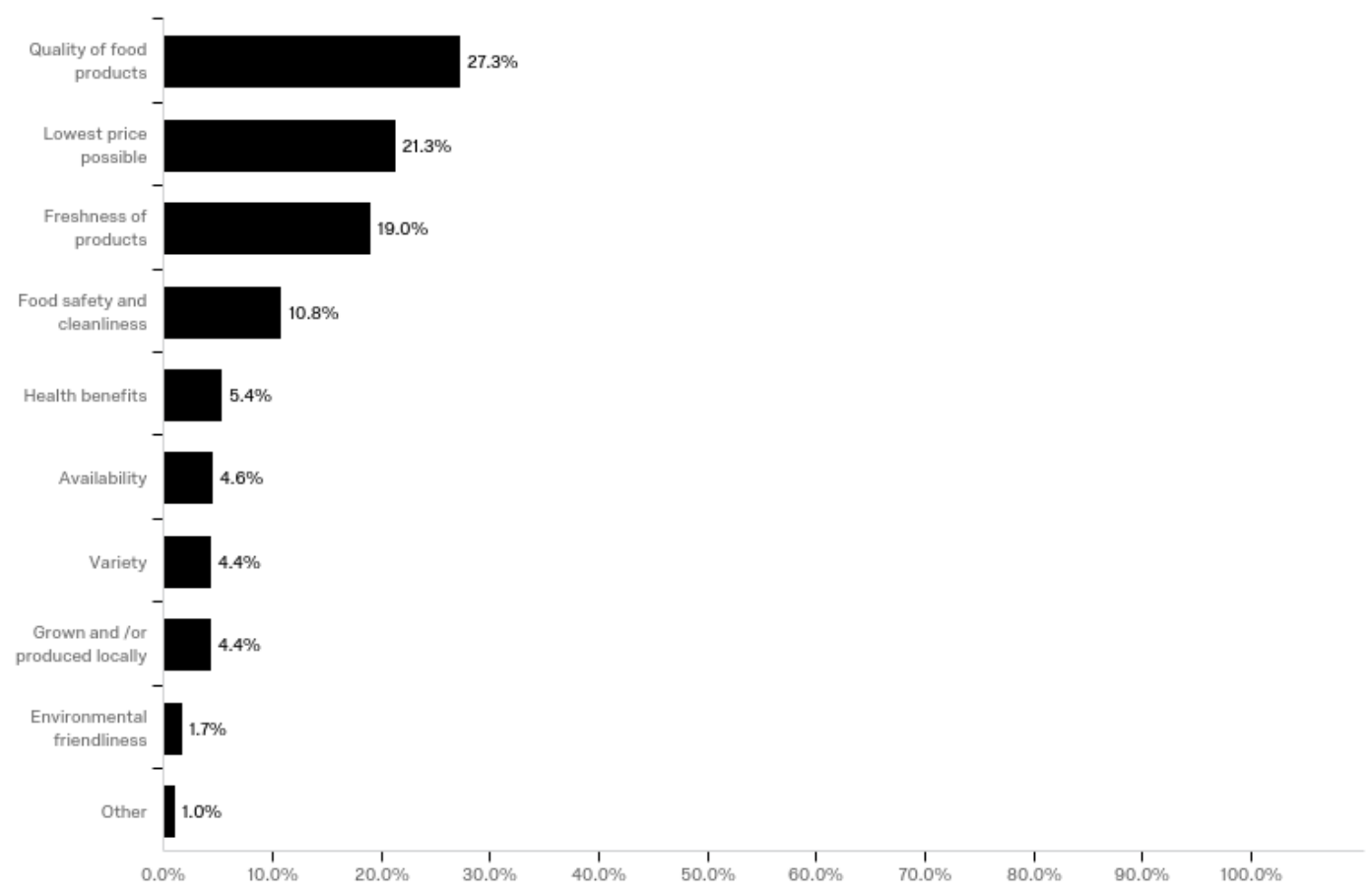

Figure 6 
On service specificity, connecting with people seemed important for respondents. A total of $46.1 \%$ of respondents enjoy connecting and talking with employees in a food store. However, store design appears to have been more important for respondents as the survey results show that $56.6 \%$ appreciate store design. Store assistance is also very important to respondents given that $81.7 \%$ of them value any assistance they can get when purchasing food. Only $38.8 \%$ enjoy knowing that they can talk to the manager at any time. A total of $35.9 \%$ of respondents prefer not to talk at all when visiting a food store. And finally, a question on meal kits garnered little support, as only $14.8 \%$ of respondents are using this service or are thinking about using it.

\section{Discussion}

Consumers who visit food stores more often tend to spend less time per visit. Numbers show that life is more fast paced. Younger consumers spend less time but visit more often. Regional differences are also noteworthy. What is interesting is the number of food stores consumers visit regularly. It appears an increasing number of individuals will take the time to visit several locations to find the right produce, price or freshness. Canada is an underdeveloped market when it comes to online purchasing, and results show potential for growth. The "Click and Collect" model is popular due to Canada's car economy and may expand more, but given these results we are expecting more consumers to consider buying food online once it comes available. For independent grocers, these results can be reassuring. This means consumers spend time considering options and not just go with larger outlets or shop with the dominant grocery store.

The grocery store experience is experienced by all in many ways. While some results were expected, others were surprising. On product specificity, freshness, quality and price are the most important characteristics for respondents, for most food categories. Food safety was also important for fish and seafood. Most studies suggest that price is the most important decision factor for respondents, but results show otherwise. Surprisingly, environmental friendliness and health benefits receive modest support. Prince sensitivity varies from one region to another and according to income. This highlights that price remains critical for a growing number of respondents, however, other factors are becoming more influential. Some markets are also curious and not afraid to experience new products like in Quebec. This is clearly an opportunity for independent grocers to take advantage of and can work on offering products other corporately owned stores offer.

Produce, bakery and meat speciality stores are acknowledged as important specialty stores by respondents. Consumers are willing to visit specific stores for their expertise in one food category. This also could be addressed by independent stores more so than corporate models.

With management specificity, Canadians are looking for different things. The one-stop shop is still very popular, and small is not as valued, except in Ontario and Quebec. Grocers are acquiring pharmacy chains to offer a small store feel when shopping for food. These results show that more work is required to make consumers enjoy smaller food stores, or stores where other items can be found. Younger consumers, and people living in urban areas, appreciate knowing someone who works in the food store they visit. This points to how familiarity is important. Closeness to the community, and even family ownership was not as important as expected, but consumers clearly appreciate finding assistance when needed. This is a significant discovery when considering service specificity. Robotics by way of self-checkouts are becoming more prominent, but the need for customized assistance, some human attention, is valued. To add to the notion of service, design appears slightly more important than people, but not by much. Knowing the manager to the person garnered modest support. This may be since human interactions are seen as a feature that can enhance the food purchasing experience. In other words, consumers want to talk to someone, if the person can help, whether it is the owner of not. Finally, meal kits are not overly popular but it is something we see more and more in groceries. For independent grocers, offering support and human interaction to customers is critical, as it is not always offered in corporately owned stores. Main factors are presented in Figure 7. 


\begin{tabular}{|r|}
\hline Service specificity \\
\hline Assistance is key \\
\hline Online potential \\
\hline Swnership, Asset and Management specificity \\
\hline Management does not matter \\
\hline Location significant factor \\
\hline Everything in one location is key \\
\hline Community Engagement and Trust are key \\
\hline Product specificity \\
\hline Produce, bakery, meat (in order) most \\
popular specialty stores \\
\hline $\begin{array}{r}\text { Quality, price and freshness (in order) } \\
\text { are most important factors for respondents }\end{array}$ \\
\hline $\begin{array}{r}\text { Environmental friendliness and locally grown } \\
\text { important factors in some regions }\end{array}$ \\
\hline Curiosity potential driver \\
\hline
\end{tabular}

Figure 7

When looking at these results, independent grocers can differentiate in a few different ways. Service are the most obvious, followed by products. Service can easily be attended, whereas products are more relevant to how management addresses procurement of supply-side issues. Important factors perceived by consumers in relation to products are applicable for any type of stores. Freshness, price, quality and food safety are generally expected anywhere food is purchased. Factors like health benefits, variety and local sourcing could provide an advantage to independent grocers, but they did not rank high. They are nonetheless worth considering for independent store owners. As for management, results are not overly conclusive as consumers tend not to know who owns and operate food stores. The survey suggests that consumers appreciate an in-store experience that offers support and assistance, no matter who is available.

Some limitations should be considered when reviewing results of this study. First, the conceptual framework was introduced for this study and requires further development. An increasing number of grocers do offer ready-to-eat solutions which fits in between service and product specificity. The grocerant phenomena, which mixes the concept of groceries with restaurants, could be incorporated in the model. Also, the sample was small when considering regional differences. This exploratory study depicted significant differences between regions on some aspects of the model. The differences merit a more thorough investigation. Independent grocers are grossly misunderstood, which is why the design of this study was so challenging. More research should look at their socio-economic contribution and how it these outlets can serve a more fragmented marketplace when it comes to food purchasing.

\section{Conclusion}

The aim of this exploratory study is to pinpoint what could allow independent grocers to prosper in a new food economy in which consumer demand is becoming more fragmented (Bean, 2017). To our knowledge, this is the first study of its kind in Canada. Organically or locally grown, fair trade, gluten-free, a growing number of criteria are being considered by consumers. As part of this study we sought to identify opportunities and strategies for rural and urban independent grocery stores, which would allow them to define ways for differentiation. This study offers insightful paths which can provide opportunities for independent grocers. The number of independent food stores has continued to drop for several years in Canada and it is difficult to see how that trend may change. However, independent stores can obtain better support through more research in order for them to become more effective in serving consumers.

\section{References}

Balazic, S., Wilcock, A., Hill, A., \& Charlebois, S. (2013). Food safety performance: labeling and indications of allergens. Food Prot Trends, 33(4), 232-9.

Ballantyne-Brodie, E., \& Telalbasic, I. (2017). Designing local food systems in everyday life through service design strategies. The Design Journal, 20(Sup1), 3079-3095.

https://doi.org/10.1080/14606925.2017.1352816 
Barcellos, M. D. de., Bossle, M. B., Gattermann, P. M., \& Vieria, L. (2015). Consumption of Eco-Innovative Food: How Values and Attitudes Drive Consumers' Purchase of Organics? REMark, 14(1), 110.

Bardenhagen, C., Pinard, J., Pirog, C., \& Yaroch, A. (2017). Characterizing Rural Food Access in Remote Areas. Journal of Community Health, 42(5), 1008-1019. https://doi.org/10.1007/s10900-017-0348-1

Bean, J. (2017). Cornering the Market: Independent Grocers and Innovation in American Small Business. The Journal of American History, 103(4), 1054-1054. https://doi.org/10.1093/jahist/jaw554

Canadian Federation of Independent Grocers - Open Letter To The Competition Bureau Of Canada. (2017, December 21). Canada NewsWire, p. Canada NewsWire, Dec 21, 2017.

Chabaud, D., \& Codron, J. (2005). How to integrate the specificities of some food departments into a retail store organization?. International Journal of Retail \& Distribution Management, 33(8), 597-617. https://doi.org/10.1108/09590550510608395

Charlebois, S., \& Amit, S. (2014). Abattoirs, meat processing and managerial challenges: A survey for lagging rural regions and food entrepreneurs in Ontario, Canada. International Journal of Rural Management, 10(1), 1-20. https://doi.org/10.1177/0973005214526504

Charlebois, S., \& Ronald, D. C. (2007). Environmental uncertainty and vertical integration in a small business network: The case of Natural Valley Farms Inc. Journal of Enterprising Communities: People and Places in the Global Economy, 1(3), 252-267. https://doi.org/10.1108/17506200710779558

Charlebois, S., \& Sanaz, H. (2015). The perceived value of dairy product traceability in modern society: An exploratory study. Journal of dairy science, 98(5), 3514-3525. https://doi.org/10.3168/jds.2014-9247

Charlebois, S., Mccormick, M., \& Foti, L. (2017). Produce Retail Price Volatility and Perceptions in the Canadian Market: Nutrition Security Variances. Journal of International Food \& Agribusiness Marketing, 29(2), 178-196. https://doi.org/10.1080/08974438.2017.1303656

Charlebois, S., McCormick, M., \& Juhasz, M. (2016). Meat consumption and higher prices. British Food Journal, 118(9), 2251-2270. https://doi.org/10.1108/BFJ-03-2016-0121

Charlebois, S., Rita, H. S., \& Mary, B. (2014). Sharing and preparing: cross-institutional, food security-based knowledge in Canada. International Journal of Sustainable Development \& World Ecology, 21(6), 532-539. https://doi.org/10.1080/13504509.2014.971905

Charlebois, S., Sterling, B., Haratifar, S., \& Naing, S. (2014). Comparison of Global Food Traceability Regulations and Requirements. Comprehensive Reviews in Food Science and Food Safety, 13(5), 1104-1123. https://doi.org/10.1111/1541-4337.12101

Cochoy, F. (2018). "Making people buy and eat differently": Lessons from the modernisation of small independent grocery stores in the early twentieth century. Review of Agricultural, Food and Environmental Studies, 99(1), 15-35. https://doi.org/10.1007/s41130-017-0046-5

Condon, G. (2016). THE INDEPENDENT LIFE. Canadian Grocer, 130(7), 26-29, 31.

French, M. (2008). Cultures of service: Strategies of Scottish grocers, 1915-1965. The International Review of Retail, Distribution and Consumer Research, 18(3), 269-282. https://doi.org/10.1080/09593960802113794

Gómez, M. I., Barrett, C. B., Buck, L. E., \& Groote, H. (2011). Research Principles for Developing Country Food Value Chains. Science, 332(6034), 1154-1155. https://doi.org/10.1126/science.1202543

Hanawa, P. H., \& Procter, D. (2018). A case study of independent grocers in the U.S. rural Midwest. Journal of Hunger \& Environmental Nutrition, 1-24. https://doi.org/10.1080/19320248.2018.1434096

Howard, V. (2017). Book Reviews: Cornering the Market: Independent Grocers and Innovation in American Small Business. The Journal of Economic History, 77(4), 1238-1239. https://doi.org/10.1017/S0022050717000961

Labrecque, J., Dulude, B., \& Charlebois, S. (2015). Sustainability and strategic advantages using supply chain-based determinants in pork production. British Food Journal, 117(11), 2630-2648. https://doi.org/10.1108/BFJ-02-2015-0068

Le Vallée, Jean-Charles, \& Sylvain, C. (2015). Benchmarking global food safety performances: the era of risk intelligence. Journal of food protection, 78(10), 1896-1913. https://doi.org/10.4315/0362-028X.JFP-15-044

Massa, S., \& Testa, S. (2011). Beyond the conventional-specialty dichotomy in food retailing business models: An Italian case study. Journal of Retailing and Consumer Services, 18(5), 476-482. 
https://doi.org/10.1016/j.jretconser.2011.06.014

Morgan, E., Hawkes, C., Dangour, A., \& Lock, K. (2018). Analyzing food value chains for nutrition goals. Journal of Hunger \& Environmental Nutrition, 1-19. https://doi.org/10.1080/19320248.2018.1434106

Morrisa, M., Schindehutteb, M., Allenc, J. (2005). The entrepreneur's business model: Toward a unified perspective. Journal of Business Research, 58(6), 726-735. https://doi.org/10.1016/j.jbusres.2003.11.001

Mortimer, G., \& Clarke, P. (2011). Supermarket consumers and gender differences relating to their perceived importance levels of store characteristics. Journal of Retailing and Consumer Services, 18(6), 575-585. https://doi.org/10.1016/j.jretconser.2011.08.007

Nasser, R., Cook, S., Bashutski, M., Hill, K., Norton, D., Coleman, J., Walker, S., \& Charlebois, S. (2011). Consumer perceptions of trans fats in 2009 show awareness of negative effects but limited concern regarding use in snack foods. Applied Physiology, Nutrition, and Metabolism, 36(4), 526-532. https://doi.org/10.1139/h11-045

Nguyen, L. (2017, July 26). Loblaw expects higher minimum wage rules will increase its labour costs by $\$ 190 M$. The Canadian Press.

Raikes, P., Jensen, M. F., \& Ponte, S. (2000). Global commodity chain analysis and the French filiere approach: comparison and critique. Econ Soc., 29(3), 390-417. https://doi.org/10.1080/03085140050084589

Reguera, M., Peleg, Z., \& Blumwald, E. (2011). Targeting metabolic pathways for genetic engineering abiotic stress-tolerance in crops. BBA - Gene Regulatory Mechanisms, 1819(2), 186-194.

Robinson, C., \& Leonhardt, J. (2018). Consumer Innovativeness and Loyalty to Non-GMO Foods: The Role of Cognitive and Affective Beliefs. Journal of Food Products Marketing, 24(1), 39-55. https://doi.org/10.1080/10454446.2017.1244789

Rodríguez-Entrena, M., \& Salazar-Ordónez, M. (2013). Influence of scientific-technical literacy on consumers' behavioural intentions regarding new food. Appetite, 60(1), 193-202. https://doi.org/10.1016/j.appet.2012.09.028

Rzymski, P., \& Królczyk, A. (2016). Attitudes toward genetically modified organisms in Poland: To GMO or not to GMO?. Food Security, 8(3), 689-697. https://doi.org/10.1007/s12571-016-0572-z

Skinner, K., Pratley, E., \& Burnett, K. (2016). Eating in the City: A Review of the Literature on Food Insecurity and Indigenous People Living in Urban Spaces. Societies, 6(2), 7. https://doi.org/10.3390/soc6020007

Stevenson, G., Clancy, K., King, R., Lev, L., Ostrom, M., \& Smith, S. (2011). Midscale food value chains: An introduction. Journal of Agriculture, Food Systems, and Community Development, 1(4), 27-34. https://doi.org/10.5304/jafscd.2011.014.007

Turner, K. (2017). S usan V. S pellman . Cornering the Market: Independent Grocers and Innovation in American Small Business. The American Historical Review, 122(4), 1239. https://doi.org/10.1093/ahr/122.4.1239

Valceschini, E. (2000). Information of consumers about GMO and "non-GMO" labelling. Oleagineux Corps Gras Lipides, 5, 399-403. https://doi.org/10.1051/ocl.2000.0399

Valente, M., \& Chaves, C. (2018). Perceptions and valuation of GM food: A study on the impact and importance of information provision. Journal of Cleaner Production, 172, 4110-4118. https://doi.org/10.1016/j.jclepro.2017.02.042

Valleé, J., \& Charlebois, S. (2015). Benchmarking Global Food Safety Performances: The Era of Risk Intelligence. Journal of Food Protection, 78(10), 1896-913. https://doi.org/10.4315/0362-028X.JFP-15-044

Walden, M. L. (1990). Testing implications of spatial economics models: Some evidence from food retailing. The Journal of Consumer Affairs, 1, 24-43. https://doi.org/10.1111/j.1745-6606.1990.tb00257.x

Wong, A. Y. T., \& Chan, A. W. K. (2016). Genetically modified foods in China and the United States: A primer of regulation and intellectual property protection. Food Science and Human Wellness, 5(3), 124-140. https://doi.org/10.1016/j.fshw.2016.03.002

Wunderlich, S., \& Gatto, K. (2015). Consumer perception of genetically modified organisms and sources of information. Advances in Nutrition (Bethesda, Md.), 6(60). 854-51. https://doi.org/10.3945/an.115.008870 


\section{Appendix A: Consent Documents and Research Instrument}

Canadian Survey on independent grocers

You are invited to take part in a research study being conducted by Dr. Sylvain Charlebois, Professor in Food Distribution and Policy at Dalhousie University. The main objective of this research is to better understand what is expected from Canadian consumers when dealing with independent grocers.

This online survey ends on October 1, 2018. Your participation in this survey is voluntary but very important as it will help us better understand how Canadians feel about food retailers in general, and how this may influence consumption habits. Survey results will be shared broadly (no identifying information on participants will be shared) and may be published in a peer-reviewed academic journal.

This survey should take approximately 10 minutes of your time. You need to have been living in Canada for at least the last 12 months and be 18 years of age or older in order to qualify for this survey.

Please select your choice below. You may print a copy of this consent form for your records.

Clicking on the "Agree" button indicates that:

- You have read the above information

- You voluntarily agree to participate

- You are 18 years of age or older

- You have been living in Canada for at least the last 12 months

This survey is conducted over the internet using Qualtrics. Your privacy and confidentiality will be protected throughout this study. Data from the survey will be stored on a secure Dalhousie University server. We will not be collecting any identifying information such as your name, email or IP address. Therefore, your responses will remain anonymous. No one will be able to identify you or your answers and no one will know whether or not you participated in the study.

Your participation in this research is entirely voluntary. You do not have to answer any questions that you do not want to answer, and you are welcome to withdraw from the survey at any time if you no longer want to participate. All you need to do is close your browser. Incomplete surveys will not be included in the analysis. Information that you provide to us through this survey will be collected anonymously. The anonymous nature of this survey means that if you complete the survey and change your mind later, we will not be able to remove the information you provided, as we will not know which survey response is yours.

If you have questions at any time about the study or the procedures, you may contact Dr. Sylvain Charlebois via email at sylvain.charlebois@dal.ca

If you have any ethical concerns about your participation in this research, you may contact Research Ethics at Dalhousie University at ethics@ dal.ca (please reference REB file \# 2018-4450).

Clicking on the "Agree" button indicates that:

- You have read the above information

Grocery shopping habits

1. How many stores do you regularly visit for your grocery shopping?

a. One

b. Two

c. Three

d. More than three

e. I do not grocery shop (skip to dietary restrictions)

2. How many times a month to visit a store where you purchase food?

a. Once

b. Twice

c. Three times

d. More than three times

e. Every other day 
3. On average, how much time do you spend in the store every visit?

a. Between 5 and 10 minutes

b. Between 10 and 20 minutes

c. Between 20 and 30 minutes

d. Anywhere between 30 minutes to an hour

e. More than an hour

4. Have you purchased groceries online?

a. Not yet, and not planning to

b. Not yet, but I'm thinking about it

c. Yes, I purchase food online occasionally (once a month)

d. Yes, I purchase food online regularly (every week)

5. Have you used a "click and collect" service before?

a. Not yet, and not planning to

b. Not yet, but I'm thinking about it

c. Yes, I purchase food online occasionally (once a month)

d. Yes, I purchase food online regularly (every week)

6. Most often, how do you get the store(s) you visit for your grocery shopping?

a. I walk

b. I bike

c. I take the bus or subway

d. I fetch a cab

e. I drive

7. How often do you use self-checkouts when grocery shopping?

a. Never

b. Occasionally

c. All the time

d. My store does not have self-checkout units

8. Do you know if the store, or any of these stores are independently owned?

a. Yes

b. No

9. Do you regularly visit (at least once a month) a store where meat is primarily sold?

a. Yes

b. No

10. Do you regularly visit (at least once a month) a store where produce is primarily sold?

a. Yes

b. No

11. Do you regularly visit (at least once a month) a store where bakery products are primarily sold?

a. Yes

b. No

12. Do you regularly visit (at least once a month) a store where fish and seafood are primarily sold?

a. Yes

b. No 
13. Do you regularly visit (at least once a month) a farmers' market?

a. Yes

b. No

14. Do you regularly visit (at least once a month) a social enterprise (coop, non-for-profit, etc...) which sells food?
a. Yes
b. No

Dietary restrictions and choices

1. As a consumer, I consider myself a...

a. Vegetarian (diet free of meat, fish, and fowl flesh)

b. Lacto-ovo vegetarians (diet free of animal flesh but eat eggs and milk products)

c. Vegan (all animal-based products, including honey)

d. Raw foodists (eat mainly raw fruits, vegetables, legumes, sprouts, and nuts)

e. Flexitarian (vegetarians who occasionally eat meat and fish)

f. Consumer with no dietary preferences

g. Other

2. Do you suffer from any food allergies?

a. Yes

b. No

3. Do you have any food intolerances?

a. Yes

b. No

4. Do you like spicy foods?

a. Yes

b. No

5. Do you sometime buy a food product without really knowing what it is?

a. Yes

b. No

6. On average how often do you buy ingredients or food products for the very first time?

a. Never

b. Rarely

c. Almost every week

d. Almost every day

Please indicate whether you agree or disagree with the following statements.

(Ownership, store)

1. I will pick a food store based on where it is located

a. Strongly Agree

b. Somewhat agree

c. Neither agree nor disagree

d. Somewhat disagree

e. Strongly disagree

2. I will pick a food store because it has everything I need in one place

a. Strongly Agree 
b. Somewhat agree

c. Neither agree nor disagree

d. Somewhat disagree

e. Strongly disagree

3. I really enjoy walking in very large food stores

a. Strongly Agree

b. Somewhat agree

c. Neither agree nor disagree

d. Somewhat disagree

e. Strongly disagree

4. I prefer visiting smaller stores where I can quickly see everything the store has to offer

a. Strongly Agree

b. Somewhat agree

c. Neither agree nor disagree

d. Somewhat disagree

e. Strongly disagree

5. I will pick a food store because I know many people who work there

a. Strongly Agree

b. Somewhat agree

c. Neither agree nor disagree

d. Somewhat disagree

e. Strongly disagree

6. I will pick a food store because I personally know the manager

a. Strongly Agree

b. Somewhat agree

c. Neither agree nor disagree

d. Somewhat disagree

e. Strongly disagree

7. Knowing who owns the food store I visit regularly is important to me

a. Strongly Agree

b. Somewhat agree

c. Neither agree nor disagree

d. Somewhat disagree

e. Strongly disagree

8. It is important for me to visit a food store that is own and operated by a family

a. Strongly Agree

b. Somewhat agree

c. Neither agree nor disagree

d. Somewhat disagree

e. Strongly disagree

9. It is important for me to visit a food store that is own and operated by owners heavily engaged with the community

a. Strongly Agree 




11. Generally, what is the most important factor you consider when purchasing food products? (pick in order)

a. Freshness of products

b. Lowest price possible

c. Quality of food products

d. Availability

e. Variety

f. Environmentally friendliness

g. Food safety and cleanliness

h. Health benefits

i. Grown and /or produced locally

12. What is the most important factor you consider when purchasing meat products? (pick in order)

a. Freshness of products

b. Lowest price possible

c. Quality of food products

d. Availability

e. Variety

f. Environmentally friendliness

g. Food safety and cleanliness

h. Health benefits

i. Grown and /or produced locally

13. What is the most important factor you consider when purchasing produce? (pick in order)

a. Freshness of products

b. Lowest price possible

c. Quality of food products

d. Availability

e. Variety

f. Environmentally friendliness

g. Food safety and cleanliness

h. Health benefits

i. Grown and /or produced locally

14. What is the most important factor you consider when purchasing fish and seafood products? (pick in order) 

a. Freshness of products
b. Lowest price possible
c. Quality of food products
d. Availability
e. Variety
f. Environmentally friendliness
g. Food safety and cleanliness
h. Health benefits
i. Grown and /or produced locally

15. What is the most important factor you consider when purchasing bakery products? (pick in order)
a. Freshness of products
b. Lowest price possible
c. Quality of food products
d. Availability
e. Variety
f. Environmentally friendliness
g. Food safety and cleanliness
h. Health benefits
i. Grown and /or produced locally

(Service)

1. I enjoy talking and meeting people I know while grocery shopping

a. Strongly Agree

b. Somewhat agree

c. Neither agree nor disagree

d. Somewhat disagree

e. Strongly disagree

2. The inner store experience, and the design of the store is very important to me

a. Strongly Agree

b. Somewhat agree

c. Neither agree nor disagree

d. Somewhat disagree

e. Strongly disagree

3. It is important for me to be able to ask for some assistance if I need it when I grocery shop

a. Strongly Agree

b. Somewhat agree

c. Neither agree nor disagree

d. Somewhat disagree

e. Strongly disagree

4. It is important for me to know I can talk to the owner or the manager at any time during my visits to the grocery store
a. Strongly Agree
b. Somewhat agree
c. Neither agree nor disagree 
d. Somewhat disagree

e. Strongly disagree

5. I prefer not to talk to anyone when visiting a grocery store

a. Strongly Agree

b. Somewhat agree

c. Neither agree nor disagree

d. Somewhat disagree

e. Strongly disagree

6. I think self-checkout lanes are a good idea

a. Strongly Agree

b. Somewhat agree

c. Neither agree nor disagree

d. Somewhat disagree

e. Strongly disagree

7. I subscribe to a meal kit service or I am thinking of using a meal kits service eventually

a. Strongly Agree

b. Somewhat agree

c. Neither agree nor disagree

d. Somewhat disagree

e. Strongly disagree

(Determinants)

8. What is your gender?

a. Male (1)

b. Female (2)

c. Other (3)

9. What is your marital status?

a. Single (1)

b. Married (2)

c. Divorced or separated (3)

10. Are you of Aboriginal decent?

a. Yes

b. No

11. Which of the following best represents your racial or ethnic heritage?

a. Caucasian

b. South Asian

c. Chinese, Black

d. Filipino

e. Latin American

f. Arab, Southeast Asian

g. West Asian

h. Korean

i. Japanese 


\section{j. Other}

12. What year were you born?
a. After 1994 (1)
b. From 1980 to 1994 (2)
c. From 1965 to 1979 (3)
d. From 1946 to 1964 (4)
e. Before 1946 (5)

13. How many children live in your household?
a. One (1)
b. Two (2)
c. Three or more (3)
d. None (4)

14. What is your education level?

a. High School Diploma (1)

b. University Degree (2)

c. Graduate Degree or Diploma (3)

d. Other (4)

15. Which province or region are you from?
a. Ontario (1)
b. Quebec (2)
c. Atlantic (3)
d. Prairies (4)
e. British Columbia (5)
f. Northern Communities (6)

16. Was your household income over the last 12 months?
a. Less than $\$ 40,000(1)$
b. Between $\$ 40,001$ and $\$ 80,000$ (2)
c. Between $\$ 80,001$ and $\$ 150,000$ (3)
d. More than $\$ 150,001(4)$

\section{Copyrights}

Copyright for this article is retained by the author(s), with first publication rights granted to the journal.

This is an open-access article distributed under the terms and conditions of the Creative Commons Attribution license (http://creativecommons.org/licenses/by/4.0/). 